\title{
When societies crash. A critical analysis of news media's social role in the aftermath of national disasters
}

Stijn Joye, Ghent University

\begin{abstract}
Apart from their primary role as news providers in disaster situations, news media can also assume a broader social role. Drawing on a critically informed qualitative content analysis of the Belgian news reporting on a national disaster, the article reveals a twofold articulation of this social role. The first consisted in newspapers highlighting the emotional dimension with potential societal implications of raising compassion and identification. Second, we found a strong articulation of a discourse of (national) unity and community, aimed at restoring the disrupted social order in the disaster's aftermath. Both aspects were discursively established by a dominant presence of emotional testimonies, strategies of personalization and by the use of inclusive language permeated with references to nation or community. The study highlights the important social role of journalism in disaster situations and events involving human suffering.
\end{abstract}

\section{Keywords}

disaster news reporting

social role of news media

mediated suffering

national disaster

qualitative content analysis

Sierre bus crash

Belgium 


\section{Introduction}

March 2012. A bus carrying schoolchildren on its way back to Belgium after a ski trip slams into the side of a highway tunnel in Sierre, Switzerland. Of the 52 people on board, 28 are killed, including the two drivers, all four teachers, and 22 of the 46 children (fifteen were Belgian, seven were Dutch). The other 24 children sustain light to serious injuries. The accident's unusually high death toll and the fact that young children were involved instantly gave rise to an excessive media coverage in Belgium, even revealing a particular dynamics in the news coverage of what was quickly defined as a national disaster: the news media partly exchanged their primary role of delivering information to the public for a role of a distinctly social nature. While scholars in the field of media and communication studies generally focus on the dominant role of news media as information providers in a context of disasters and mediated suffering (Joye 2012; Pantti, Wahl-Jorgensen, and Cottle 2012), this article explores the broader, social role of media in disaster situations.

In this article, we define disasters as collectively experienced traumatic events that result in a soci(et)al disruption of a community (van der Velden and van Middendorp 2008: 101). Here, we diverge from the dominant conceptualization of disasters that focuses on the physical and/or material damage invoked by natural or man-made events and instead follow Graber (2005) in focusing on the ramifications or threat that these events represent to the peace of mind of large numbers of citizens. Such conceptualization already indicates that news media can assume a relevant and central role in the aftermath of a disaster, identified by Perez-Lugo (2004) as the social and therapeutic role of media. Through the representation of suffering, media can raise a (temporal) sense of personal identification or a sense of community (Wayment 2004; Kitch and Hume 2007). The context allows the media to serve as central 
forums for public expressions of support, promoting a form of social collectivism with regard to the mourning process. For Armstrong (2012: 19), this is part of our contemporary Zeitgeist and society, where 'the need to talk and memorialize [death and grief] becomes expressed in cultural artifacts'. Central to many of these (scholarly) discussions is the notion of compassion which also constitutes an articulation of this important social dimension of the media, further characterized by discourses of (national) unity and community alongside various forms of solidarity, relief aid and personal involvement. In sum, as Pantti, WahlJorgensen and Cottle (2012: 61) write, '[i]t is through media representations that we bear witness to the shock, grief, fear and anger of the victims of disasters. It is also through processes of media representations that individual experiences and emotions become collective and political.'

The central question of this contribution concerns the emotional discourse articulated by news media in their reporting on disaster situations and on the (collective) process of coping or coming to terms with the traumatic event. A fair amount of literature exists that theorizes these traumatic phenomena of suffering, but they mainly do so from a memory studies perspective (Zelizer 1998; Kitch 2003; Kitch and Hume 2007; Robinson 2009), hence devoting less attention to the significant role that news media play in the direct aftermath of such events. Additionally, the mostly theoretical literature has not yet been sufficiently matched with substantial and rigorous empirical efforts. Thirdly, most of the research in the field has been conducted in relation to an Anglo-Saxon context, largely overlooking postdisaster journalism in other media systems or news cultures. Therefore, by applying a critically informed qualitative content analysis to the coverage of the Sierre bus crash in four Belgian newspapers, this article empirically examines the social role that news media assumed in the complex process of coping and collective mourning in the immediate 
aftermath of what was labeled as a national disaster. By doing so, we reflect on the important and diverse societal role of journalism in disaster situations and events involving human suffering.

\section{When 'news' ceases to be 'news': the social role of news media}

News media are essential in interpreting and giving meaning to disasters, to such extent that many scholars refer to a media construction of disasters (Benthall 1993; Ploughman 1995; Franks 2008; Joye 2010). The notion of a media construction mainly relates to the primary and dominant function of news media to inform society about the factual aspects of a disaster, in addition to providing analysis and interpretation. In recent years, however, there has been a notable increase in attention paid by researchers to the social and emotional component of this process of meaning construction. We point to a number of complimentary and broader societal functions that are attributed to news media in academic literature discussing mediated suffering. As suggested earlier, we range these under the broad denominator of social functions (Perez-Lugo 2004). This social role is mainly important to victims and their immediate surroundings or relatives, although it also bears relevance to a broader community. The latter is closely connected with the central notion of distant suffering (Boltanski 1999), which is based on the idea that the aspect of proximity does not primarily refer to geographical or emotional distance, but to the fact that it concerns human suffering that we do not witness in a direct way. For distant or uninvolved audiences, bearing witness through an engagement with 'witnessing texts' such as a news media reports (Frosh 2006) is the basic moral engagement with the suffering or death of others that compensates for a lack of immediate action (Boltanski 1999). 
In these situations, Boltanski (1999: 149-169) believes, media are assumed to play the role of direct witness, and, consequently, to report on suffering, alongside fulfilling a distinctly social role. We are specifically referring here to a soci(et)al function assumed by media in providing emotional support, coordinating a basis for collective solidarity, and facilitating the process of coping of a community or of individuals afflicted by disaster, loss and misfortune (Walter, Littlewood and Pickering 1995; Kempe 2007). Rentschler (2010) identifies such reparative practices of affective labor by journalists as key features of the news production process. Media fulfill this social role during the emergency, immediately after, or sometime later in the process of coping or at the time of commemorating, when the disaster has been accepted in a community's collective memory (Kempe 2007: 328). Perez-Lugo (2004: 219), however, situates its key value during the disaster or emergency itself, when 'the media-audience relationship [is] motivated more by the people's need for emotional support, companionship, and community ties, than for their need for official information.' Although the therapeutic role of media is mainly situated in (often ritualized) forms of self-expression by the public (Thumim 2010), media can act as central forums for public expressions of support (Kitch and Hume 2007; Cottle 2013), and promote a form of social collectivism with regard to the mourning process.

Alongside expressions of grief and mourning, the public status of the process of coping, as part of an emerging 'confessional culture' (Wardle 2007: 269), allows victims to criticize the authorities directly and to ask important questions concerning failing policy and accountability following a disaster (Pantti and Wahl-Jorgensen 2011). In this respect, Pantti and Sumiala (2009) consider the representation of a disaster as a crucial discursive instrument in the restoration and renewed legitimization of the existing power relations and hierarchies within a society and of the social order that has been put to the test by the disaster. Thus, 
within this context, disasters are viewed as a significant threat to the prevailing social order, and specifically to the hegemonic position of power held by the ruling social elite. This view holds that the coverage by news media will mainly consist in calling on the public to show compassion and empathy, with the purpose of reinforcing the population's emotional connection with the nation. Nguyen (2009: 165) speaks of a 'system of compulsory empathy' that is prominently present in reporting on national disasters.

\section{Affect and (post-)disaster journalism}

Various studies have focused on how this social role of news media has manifested itself in reports on disasters and suffering. According to Pantti and Wahl-Jorgensen (2007), newspapers usually (re)present four different basic emotions in their coverage, according to a specific pattern: first, horror in the face of what has gone wrong; next, grief or sadness over the suffered loss; followed by empathy or compassion with the victims and their relatives; and, finally, anger toward the guilty or that which is considered the cause of the suffering and harm. It is important to point out here that the existing literature mainly focuses on events where there is an obvious fault or a perpetrator who can be called accountable for the occurred misfortune. In other cases, such as the Sierre bus crash, the question of guilt or accountability is not that evident or is missing at all. It is interesting to observe the discourses that are deployed by journalists in this particular situation as existing feelings of anger cannot be targeted towards a specific cause but still have to be channeled and preferably transformed into more constructive emotions. In a later follow-up study, Pantti and Wahl-Jorgensen (2011) hinted at the larger role that news media can play in the latter case as they broadened the notion of public anger by including feelings of injustice that motivate people to take (political) action and to go public with their fight for justice and recognition. In their capacity 
of public forums, the media play an important part in channeling these emotions after a disaster.

Pantti and Wahl-Jorgensen (2011) also speak of a process of empowerment: to lend a voice to, or to acknowledge and recognize (the opinion of) ordinary citizens, who are normally ignored or even defenseless in any media debate about disasters. Chouliaraki (2013: 147) situates this within a broader tendency of 'ordinary witnessing', pointing out that journalists will make increasingly more often use of (emotional) testimonies and opinions from 'the person on the street' in order to tell a story that concerns suffering. One way to do this, for example, is by means of interviews with victims and bereaved relatives, which, according to Raphael (1986) and Vasterman (2008), ensures that their suffering and victimhood is publicly acknowledged and helps them to get a grip on the intense feelings of anxiety, loss and helplessness that they are experiencing.

These emotions manifest themselves both on an individual and a societal level. In this regard, Wijfjes (2002: 8) notes a strong tendency toward individualization, claiming that the media emphasize individual emotion and experience by granting ample room to extremely personal accounts of experience with a highly emotional content, which intensifies the public's personal identification with the suffering. Underlying this are a set of 'commercial' news values such as bad news, drama and relevance that tend to prioritize stories with a perceived appeal to target audiences (Harcup and O’Neill 2016). A frequently used way of personalizing the news coverage of a disaster consists in focusing on the victim (Christie 1986; Chermak 1995). Moeller (2002: 48-49) points to a 'hierarchy of innocence' that media apply in their depiction of disasters. Children, in their capacity of young, weak and innocent victims, are found to confer the greatest emotional intensity on a news report, followed by pregnant 
women and elderly persons. Another way in which journalists personalize their reports consists in calling on the elite - politicians, heads of state or celebrities - to speak out.

On a societal level, news media can call up a strong (temporary) sense of community in their representation of a disaster. Placing emotions at the center of the news coverage is generally considered a powerful means for imagining unified communities (Pantti, Wahl-Jorgensen and Cottle 2012). Wayment (2004) even claims that excessive media attention for a disaster can result in a unique form of identification, in which the non-involved outsider has the perception of being an equal of those who are suffering, united in being part of the same disaster-stricken community. In disasters of a smaller scale or more local nature, the media are found to play an influential part in the construction of (collective) identities, and in the forging of both imaginary and real communities (Rahman 2007). Such articulations of (national) unity and community represent the important social dimension of the overarching notion of compassion in the context of mediated suffering (Kitch and Hume 2007). It is further characterized by all kinds of forms of solidarity and involvement, such as individual and collective acts of help, gifts of charity and (silent) protest marches, in which the media can play a facilitating part (Höijer 2004). According to Kitch and Hume (2007), simply focusing on these humanitarian actions and bringing positive stories about, for example, miraculous acts of rescue, equally constitutes key components of the social role of news media. These instances of a social form of news reporting are also explained by their connection with providing moral support and collective consolation as with the strengthening of community ties. 


\section{Potential setbacks}

So far, our literature review has limited itself to a somehow positive reading of the relation between media representations of suffering and disasters and emotions of compassion and (moral) solidarity. It is also important, however, to point out a number of negative manifestations and implications of this relation.

A first and classic point of criticism in the debate concerns the observation that (individual and collective) helping behavior and solidarity are not always/simply motivated by altruistic considerations, but often serve the purpose of minimizing or even doing away with a feeling of guilt toward the other person in need (Benthall 1993). Likewise, Butler (2004) claims that the cited forms of emotional self-expression ultimately impede us in establishing actual (social) commitment. The same goes for media professionals as their interest in the social and emotional dimensions of news work could also be seen as 'the profession's response to the economic and affective conditions created by a news business dependent upon dramatic news [...] for profitability' (Rentschler 2010: 470).

Secondly, Pantti (2009: 83) stresses that, in news media, every expression or articulation of compassion as 'a moral demand to address distant suffering' is far from inexhaustible or unconditional. In other words, attention paid to one instance of suffering invariably goes at the expense of other disasters and emergencies. Evidently, this touches upon the inevitable selectivity of news media coverage (see Joye 2010).

Thirdly, several scholars refer to the often problematic relationship between media and victims or the wider public (Shearer 1991; Jemphrey and Berrington 2000; Rentschler 2010). 
Our case study of the Sierre bus crash, for example, aptly illustrates how news media sometimes transgress the boundaries of moral decency, ethics and respect for the privacy of victims, survivors and relatives, which may add to the already present grief. Incorrect or biased reporting also has a potentially negative or even traumatic impact on the persons involved (Maercker and Mehr 2006). Evidently, all of this is related to the deeply human feelings associated with situations of suffering and disasters.

In what follows, we go deeper into these different dimensions by means of a critically informed qualitative content analysis of news reporting on the tragic bus accident in Sierre, Switzerland in March 2012. The high degree of relevance or (emotional) proximity and the scale of the disaster generated plenty of media attention and resulted in a qualification as a national disaster. While Belgium has largely been spared from large-scale (natural or manmade) disasters in the recent past, the Sierre bus crash incurred such emotional and psychological appurtenances that a community was disrupted, not only testified by the amount of media attention but also by the event monopolizing everyday discourses and practices for a considerable amount of time. The underlying objective of this study is to explore tentatively how the Belgian news media assumed their social role in this post-disaster period, thus potentially becoming a channel or public forum for the Belgian public's emotions. The relevance of studying Belgian journalistic practices and the related news culture further draws on Belgium being designated to Hallin and Mancini's (2004) democratic corporatist model. This model is characterized by a high degree of journalistic professionalism and a long tradition of self-regulation, and particularly these two elements were heavily criticized in the public debate following the crash and the way media covered it. Nevertheless, our case does show how media practitioners such as journalists can and/or should assume a role which at 
first sight diverges from their core professional values and tasks but has potentially wide and positive ramifications for a suffering and mourning society.

\section{Methodology and data}

On a methodological level, we follow Pantti (2009:. 89-90) in her suggestion to regard (news) narratives as means of understanding the social world, in addition to Chouliaraki's (2010: 104) reference to media texts or mediated representations as symbolic power that "coexists with and reproduces, but may also change, dominant relationships of power (economic, political, and cultural).' News media in particular are believed to reflect 'the social, economic and political structures within which they operate' (Ploughman 1997: 119). Therefore, a critical approach to the disaster coverage under study should move these processes of construction into the foreground of the analysis. In this article, we apply a critically informed qualitative content analysis (Fields 1988; Hijmans 1996) to investigate how human suffering and emotions are represented and how meaning is constructed and transmitted within a specific social context. Acknowledging the need for closer empirical engagement with and a basic understanding of news media's social role in covering national disasters, we have opted for a critically informed qualitative content analysis (Hsieh and Shannon 2005).

The basic unit of our analysis was a newspaper article. The study sample consists of all newspaper articles that were published up until one month after the Sierre disaster in the four most popular national Dutch-speaking dailies De Morgen, De Standaard, Het Nieuwsblad and Het Laatste Nieuws. A cumulative search of the terms 'bus accident' and 'Sierre' to the said period of time (March 14, 2012 until April 14, 2012) in digital press database Mediargus initially resulted in a total sample of 327 articles, of which 215 actually reported about the bus 
accident in Sierre and its aftermath. The mid-market newspapers Het Laatste Nieuws $(\mathrm{N}=78)$ and Het Nieuwsblad $(\mathrm{N}=77)$ published considerably more articles than their up-market counterparts De Standaard $(\mathrm{N}=38)$ and De Morgen $(\mathrm{N}=22)$.

After an initial coding stage, the data were compared and integrated into one dataset. At this point, it became clear that a substantial part of the articles only mentioned the bus accident in the margin of a different story. Thus, many articles merely devoted a short sentence to the disaster in order to explain, for example, the postponing of certain events, such as carnival parades, or the observing of a minute of silence before a football match. Consequently, the relevance of these pieces to the study's object of inquiry was negligible. Next, we analysed the dataset in several cycles, abstracting the data into two distinct categories of discourse while acknowledging the wider political, social and cultural context. Central to the empirical inquiry is the following question: how is the social role of the selected news media articulated in their reporting on the disaster? This implies that the analysis does not focus on the factual process of information dissemination, and only to a lesser extent on the publicly held debate concerning the failure of journalists to act in accordance with certain deontological guidelines. Instead, the empirical focus of the analysis lies on the articulation of discourses related to the social role of news media. We examined textual as well as visual articulations as approximately $70 \%$ of all articles in the sample featured pictures.

\section{Findings and discussion}

While asking the question of what (visual and textual) language has been used by the journalists in reporting on the bus crash, two key discourses emerged from our qualitative content analysis: an emotional discourse and a discourse of unity and community. In addition 
to a textual analysis of these two core discourses, both were framed in their wider political, social and cultural context which enabled us to critically assess them.

\section{The emotional discourse}

A first look at the news attention cycle during the selected period instantly reveals that the observed newspapers devoted plenty of space to the emotional component in their reporting. Many articles continued to cover the bus accident in Switzerland up until several weeks after it happened. From a narrow scientific point of view, and strictly considering content, it is rather difficult to explain this prolonged attention. The facts, after all, were known, and already a few days after the accident, the reports provided hardly any or no new information about the drama. This shows us that the news value of the bus crash quickly ceased to be derived from the event itself, but was urged on by a secondary wave of emotions based on the criterion of proximity. As noted earlier, this factor of proximity cannot solely be expressed in terms of geographical distance, but should undeniably also be regarded as an emotional factor, related to recognizability and identification. At the heart of the event lies human suffering, with which personal identification is possible, and which particularly applies to all those who have children of their own. This emotional discourse based on compassion is reflected in different ways in the news content.

First, journalists appeal to a wide register of emotions in terms of language, employing many frequently used adjectives and phrases such as 'heartbreaking'1 (Het Laatste Nieuws March 15, 2012: 1), ‘intense' (Het Nieuwsblad March 16, 2012: 30), 'dismay’ (De Morgen March 16, 2012: 26), 'unreal' (De Standaard March 23, 2012: 10), 'weighing heavily' (Het Nieuwsblad March 16, 2012: 8) and 'we will never forget you' (Het Nieuwsblad March 22, 
2012: 4). The newspapers also clearly suggest that the only appropriate answers to the drama are silence and serenity, illustrated by telling headings of editorials written by editors-in-chief or commentators - 'Let the silence speak' (De Standaard March 16, 2012: 2), 'Silence' (De Morgen March 16, 2012: 1) and 'Peace' (Het Nieuwsblad March 15, 2012: 2) - or by one paper's front page headline: 'One minute of silence for them' (Het Laatste Nieuws March 16, 2012: 1). The newspapers consequently also paid a lot of attention to the various initiatives of honoring a minute of silence in memory of the deceased (see below).

Secondly, we find a remarkable articulation of the social role of media in a series of interviews and special dossiers that gave the floor to psychologists and trauma experts. These pieces go deeper into the physical and psychological pain and provide answers to questions about coping with loss, the (long-term) process of closure, and parting. They offer tips that are often very specific and directly aimed at the public, including phone numbers of relevant public services or professional counseling services such as the Kinder-en Jongerentelefoon (Children and Youth Help Line) or peer support associations for families with young road casualties. To a certain extent, news media here take over the role of the confidential advisors that are already present in a society, such as priests, doctors and psychologists - echoing Willis' understanding of trauma reporting or disaster journalism 'as a kind of professional priesthood' (2010: 13).

A third articulation of the emotional discourse is found in the large proportion of testimonials, reactions and personal experience stories that offer highly emotional content and come from involved children, parents, relatives, aid workers and so-called members of the elite. For example, several newspapers publish photos of the chalk messages left by the parents on the tunnel wall in Sierre, casting a very intimate look at the emotions of those directly involved. 
A variation on this category is found in articles that cite persons who have lost a child in similar circumstances or who have been themselves victims of a bus accident. This offers gripping stories about the personal trauma of loss and parting that never wears off. The 'voice' of the children that passed away in Switzerland is also indirectly raised in newspaper reports using pictures and bits of text that were retrieved from the blogs and websites created at the occasion of the ski trip. These very personal stories allow the audience to better know them and mourn their death which is symbolically represented as meaningful and valuable to a larger society. As was previously mentioned, an important component of the social role of news media also consists in bringing positive stories. These render the suffering more bearable by hinting at hope and piercing the dominant negative image. In this way, articles covering a number of children's full recovery, awakening from coma or return to Belgium, provide moral support and collective consolation.

These different discursive articulations cumulate in a peak of the emotional attention curve when the collective funeral ceremonies take place between March 21 and March 23. The presence of many members of the social/political elite - i.e. the royal families of Belgium and the Netherlands, then European President and former Belgian Prime Minister Herman Van Rompuy, different domestic and foreign Prime Ministers and Ministers - and of famous media personalities and celebrities constitute an important (personalized) angle for the newspapers to cover the ceremony. In general, however, these remain secondary to the dominant theme of grief and suffering. Several pictures zoom in on grieving family members and spectators, yet a singularly powerful emotional image is found in pictures portraying the row of small white coffins. This is affirmed by the fact that all newspapers run these pictures, often on the front page. Combined with literal bits of text retrieved from farewell speeches, speeches and read 
aloud letters from the children, this results in a particularly personal and intimate coverage of the funeral ceremonies, clearly aimed at emotionally involving the public.

In addition, the discourse analysis confirms the already discussed hierarchy of innocence. In this respect, a sentence such as 'The horrific bus accident in Switzerland hits us where we are most helpless: our children' (De Standaard March 15, 2012: 2), or the term 'little angels' used as a synonym for the deceased children, clearly illustrate that the Belgian newspapers primary focus is obviously on the young children. This is also reflected in the visual choices made by the newspapers. They publish plenty of photographic material featuring injured children in wheelchairs, on crutches, or with a plaster cast, but equally bring the prominent images of the white coffins, thus reinforcing the emotional dimension of the story. Pictures of the deceased children also figured on the front pages of several newspapers. This, however, raised critical questions concerning the deontological code observed (or not) by journalists and the respect shown for the victims' privacy. Specifically, the fact that the visual material was picked from social networking sites without the parents' prior consent brought about a lot of public criticism (cf. infra). As far as textual material was concerned, we found different citations retrieved from blog posts or letters, addressed by the deceased children to their family.

Discursively, both the images and the text excerpts served as a material manifestation or concretization of the abstract feelings of psychological and physical pain caused by the loss. In this way, news media lend a face to the unfathomable sadness, instantly rendering it tangible for the public. As so-called 'ideal victims', the children clearly received more coverage than the adult victims. Moreover, the adults were submitted to a certain hierarchy of suffering. The children's supervisors and teachers were discursively represented as separate 
from the bus drivers. The latter carried along a certain degree of perceived guilt, which existed solely in the eye of the beholder, as there was/is no evidence to support this.

\section{A discourse of unity and community}

A second core discourse of unity and community is closely related to the process of grieving and that of coming to terms with the loss that goes hand in hand with it. The newspapers abundantly report on the mourning registries that are opened all over the country or via online platforms, the messages of condolence received from foreign heads of state, the flowers and teddy bears laid down at the entrances of the afflicted schools, the great sense of solidarity, etc.

At the heart of this is the construct of a collective (national) identity. The fact that the suffering and mourning are collective and, in addition, transcend all boundaries of language and culture, is emphasized by the dominant use of the inclusive 'we'-form and by specific phrases, such as: 'This grief affects everyone' (emphasis added, Het Laatste Nieuws March 23, 2012: 4), 'Today is a day of national mourning' (emphasis added, De Morgen March 16, 2012: 3), 'Belgium mourns its children' (emphasis added, Het Laatste Nieuws March 24, 2012: 22), 'The entire country mourns' (emphasis added, Het Nieuwsblad March 14, 2012: 16), 'We feel for you' (emphasis added, Het Laatste Nieuws March 16, 2012: 48), 'Everyone affected, everyone connected' (emphasis added, De Standaard March 15, 2012: 13), or 'These last few days, our country has waved goodbye to our children' (emphasis added, Het Laatste Nieuws March 23, 2012: 4). Several articles zoom in on foreign news coverage and on messages of condolence sent by, among others, the Pope and representatives of the Muslim community. 
Attention is primarily focused on March 16, 2012, the day of national mourning, and on the many initiatives of observing a minute of silence at various sorts of sport events, in schools or workplaces. By means of testimonies and numerous pictures of large groups of people gathering to observe the minute of silence, the newspapers discursively show how the bus crash has emotionally affected and disrupted an entire community. The detailed reports of the funerals - usually intimate and private occasions - equally testify to the highly public and collective nature of the grieving process at that time, which also goes for the images of the attending crowd of approximately 6.000 people. In this way, news media anticipated the prevailing need for consolation and compassion that was prominently present in Belgian society.

By focusing their selection of op-ed pieces and readers' comments on the bus crash, the newspapers also transformed the existing sections dedicated to letters from readers into an intensely used public forum where the overtly shared grief could be voiced. This, for that matter, coincides with the therapeutic role of news media. For several days, the two popular newspapers Het Nieuwsblad and Het Laatste Nieuws continued to reserve their sections almost exclusively for comments spawned by the bus accident. Especially after the funeral ceremonies, many citizens made use of this public forum, which resulted in telling headings such as 'The entire country reflects on what really counts' (Het Laatste Nieuws March 23, 2012: 47), 'Unity' (Het Laatste Nieuws March 23, 2012: 47), 'To the relatives: You are not alone in this' (Het Nieuwsblad March 23, 2012: 32) or 'Strong together' (Het Laatste Nieuws March 23, 2012: 47). 
Both practices of news reporting and providing a forum to the audience, echo Butler's interpretation of grief as a moral response to death and an essentially social construct that cultivates solidarity and a sense of community by bringing relational ties to the fore (Butler 2004: 22).

\section{News in context: discursive and social practices}

Not long after the dramatic event, the news coverage was largely overshadowed by a broader

(media) debate in which the discursive practices of some newspapers were denounced. A register of emotional language clearly emerged from the textual analysis, revealing a strong personalization of the coverage. In the use of this language, however, several newspapers went off the road.

This was addressed in the form of a partially reflexive coverage or self-criticism, in which different entities - including certain news media on their own account, as well as individual journalists - called for more reflection and professional restraint in reporting. A striking observation is that not so much the predominantly emotional nature of the news reports (i.e. the 'language' in itself) was questioned, but rather the extreme articulations of these reports (e.g. articles that violated the privacy of the victims and the relatives) and certain journalistic practices (e.g. the use of blog entries and holiday pictures without prior consent, the publication of photo specials and extra editions, etc.). In this, both the popular mid-market newspapers and the so-called quality press were under fire. In a number of cases, the public debate resulted in a more sober news coverage that replaced pictures of children or grieving families by white spaces with short captions, cartoons or (close-up) images of iconic objects such as flower wreaths, teddy bears and candles. 
In the media debate, reference was also made to the fact that the sensational nature of the reporting. Overtly condemned practices such as the publishing of private pictures on the front pages could primarily be linked to what Rentschler (2010) has defined as the economic and affective conditions of the news business; a determining commercial context of production fuelled by an increasing competition between newspapers. For a more detailed analysis of the media debate, we would like to refer to Joye (2014). At this point, it suffices to point out that the excesses of the emotional language, serving as a basis for the transgressive conduct, elicited many disapproving comments from politicians, academics, journalists and public alike. Given the long tradition of self-regulation by the media, this fundamental principle of Belgian news culture found itself questioned in its very foundations. The Raad voor de Journalistiek (Council for Journalism) subsequently reacted by developing a new directive on the use of information and visual material retrieved from personal websites and social networking sites. Still, the problems that were raised and the social debate indicate a clear limit to the social role of news media and point to the perpetually fragile relationship between media and victims.

The severe criticism on the news media and displayed journalistic practices can also be related to the specific nature of our case. In contrast to other dramatic events, there was no question of guilt and no obvious perpetrators, hence no pressing or underlying need for the media to take up their role as critical watchdogs or to act as the fourth estate in order to denounce certain injustices or power abuses. It could be argued that this lack of a 'greater cause' resulted in a reduced playing field for the media and a higher demand for (moral and deontological) accountability on behalf of the journalists. One op-ed article (De Standaard March 19, 2012: 6) made a similar claim as it compared the news coverage of the Sierre bus 
crash to the reporting on the 1996 pedophilia scandal and children abductions in Belgium. Both disrupted a community, both concerned children and in both cases, some journalists crossed the border in relation to privacy and deontology but there was almost no questioning of journalistic misbehavior and accountability in the latter case. The media were then regarded as a bystander in the broader struggle for justice, incorporated in an overall feeling of the end justifying the means.

Finally, in such cases of national disasters, it is also relevant to take a look at the political and ideological dimension of the news coverage (Bailey and Barathi 2000). As already briefly mentioned in the introduction to this contribution, tragic events of this sort can disrupt a society, consequently making it of great importance to strengthen and/or restore social cohesion and order. Journalism can play a central role in this process by unifying the public into communities and nations, and by reaffirming dominant social values and norms (Kitch and Hume 2007; Robinson 2009). Combined with the discourse of unity and community, the emotional discourse that generates individual involvement also creates a strong sense of cohesion and collective identity. Acknowledging Belgium's unique political, cultural and multilingual constellation (i.e. the Dutch-speaking Flanders, the French-speaking Wallonia, the bilingual Brussels region, and a small German-speaking community), the notion of a collective or national identity is not self-evident. Nonetheless, the Dutch-speaking newspapers frequently mention in passing that for instance the French-speaking Belgian press paid equally large attention to the bus accident, thus emphasizing the national nature of the compassion and the idea of different cultural communities united in grief.

This idea of national unity gets an additional ideological articulation in the attention the newspapers devote to classical symbols of a nation and to national institutions such as the 
king and the royal family, the Belgian flag, the army, uniforms, etc. Additionally, several articles extensively shed light on the efforts made by government and authorities to look after the victims' parents and to bring home the bodies, to organize a state funeral and to offer repeated expressions of support and sympathy, which included personally opening mourning registries. All this affirms the government in its position of central (coordinating) body of authority within a society. Again, this can be linked to the specific nature of the disaster, eliciting a particular kind of news discourse. As one journalist stated; '[t]here was no one to blame. No government that failed. No emergency services that came too late. No infrastructure that was inadequate. Everyone did a perfect job' (De Standaard March 19, 2012: 6).

In the same vein should be viewed the many instances of attention devoted by newspapers to various members of the social elite. The coverage acts as an important ideological instrument for discursively restoring, reinforcing and legitimizing the social order and fabric, which has been put to the test by the disaster. A telling example of this practice is found in the following excerpt from an editorial:

Today the nation mourns its children. At $11 \mathrm{am}$, it is up to every one of us to show that we are united in grief and that we are able to turn our anger into solidarity in the face of so much injustice. (Het Laatste Nieuws March 16, 2012: 2)

\section{Conclusion}

This article offered reflections on the dual role assumed by news media in the coverage of emergencies and disasters, a topic or aspect of inquiry that is still often (empirically) 
neglected in academic research. News media do not only act as providers of factual information, but also constitute important social actors. This broad social role includes, among other elements, providing emotional support, creating a basis for collective solidarity and unity, as well as channeling feelings of anger or injustice on the part of the victims and the public. Particularly in the context of a national disaster when intense emotions of fear, anger and grief run high, this social role of media is crucial in reinforcing social order and consensus. Nonetheless, as the findings demonstrate, it also comes with some setbacks and potential risks related to privacy issues.

A critically informed qualitative content analysis of the extensive news coverage of the Sierre bus crash in Belgian newspapers indicated a dominant presence of emotional discourses in the reporting. Placing emotions at the center of the news coverage is generally considered a powerful means for imagining, unifying and reinforcing communities. The specific nature of the disaster, involving young children as main victims, as well as a high degree of proximity and involvement on the part of the public, formed the main rationale for the news discourse. Consequently, Belgian news media paid plenty of attention to the emotional dimension of the accident up until the first month following the disaster, which raised feelings of compassion and identification. This manifested itself in two kinds of reports: first, in articles that discussed the psychological and physical pain of loss, as well as the process of grieving and coping with loss that goes hand in hand with it; secondly, in different contributions that articulated a discourse of unity and community. The latter category is believed to play a vital part in strengthening the social fabric of a society struck by disaster and in building a basis for solidarity and collective mourning. Discursively, both aspects were reflected in, among other elements, the dominant presence of personal experience stories from involved children and parents that contained highly emotional content, reactions from relatives, and testimonies of 
condolence by both unknown and famous persons and authorities, up to the use of inclusive language permeated with references to nation or community. This specific content allows newspapers to anticipate the general public's desire to receive support, to find understanding and to empathize with the afflicted families by means of the public's consumption of news media.

This explorative study corroborates and on the whole endorses the important social role that news media can play in disaster situations and events involving human suffering. It also demonstrated how the particular nature of a disaster can trigger a particular set of news discourses. When there is no obvious fault or perpetrators, news media apparently operate in a stricter framework of accountability. Failure to comply might result in heavy - and rightful criticism as demonstrated by our case study. The relationship between media and public in this matter can be a delicate balancing act. Therefore, additional empirical research is required to continue to explore the audience perspective in this story and to examine, among other things, how different categories of the public (victims, survivors, relatives, aid workers and non-involved persons) experience this social role of media.

\section{References}

Armstrong, R. (2012), Mourning Films. A Critical Study of Loss and Grieving in Cinema, Jefferson: McFarland \& Company,.

Benthall, J. (1993), Disasters, Relief and the Media, London: Tauris,

Boltanski, L. (1999), Distant Suffering, Cambridge: Cambridge University Press. 
Butler, J. (2004), Precarious Life: The Powers of Mourning and Violence, London: Verso.

Chermak, S. M. (1995), Victims in the News. Crime and the American News Media, Boulder: Westview Press.

Chouliaraki, L. (2010), 'Discourse and Mediation', in S. Allan (ed.), Rethinking Communication: Keywords in Communication Research, New Jersey: Hampton Press, pp. 95108.

(2013), The Ironic Spectator. Solidarity in the Age of Post-Humanitarianism, Cambridge: Polity Press.

Christie, N. (1986), 'The ideal victim', in E. A. Fattah (ed.), From Crime Policy to Victim Policy: Reorienting the Justice System, London: Macmillan, pp. 17-30.

Cottle, S. (2013), 'Journalists Witnessing Disasters. From the Calculus of Death to the Injunction to Care', Journalism Studies, 14:2, pp. 1-17.

Fields, E. E. (1988), 'Qualitative Content Analysis of Television News: Systematic Techniques', Qualitative Sociology, 11:3, pp. 183-93.

Franks, S. (2008), 'Getting into Bed with Charity', British Journalism Review, 19:3, pp. 27 32. 
Frosh, P. (2006), 'Telling Presences: Witnessing, Mass Media, and the Imagined Lives of Strangers', Critical Studies in Media Communication, 23:4, pp. 265-84.

Graber, D. A. (2005), Mass Media \& American Politics. 7th Edition, Washington: CQ Press.

Hallin, D. C. \& Mancini, P. (2004), Comparing Media Systems: Three Models of Media and Politics, Cambridge: Cambridge University Press.

Harcup, T. \& O’Neill, D. (2016), 'What is News? News Values Revisited (Again)', Journalism Studies (online first).

Hijmans, E. (1996), 'The Logic of Qualitative Media Content Analysis: A Typology', Communications, 21:1, pp. 93-108.

Höijer, B. (2004), 'The Discourse of Global Compassion: The Audience and Media Reporting of Human Suffering', Media, Culture \& Society, 26:4, pp. 513-31.

Hsieh, H-F. and Shannon, S. E. (2005), 'Three Approaches to Qualitative Content Analysis', Qualitative Health Research, 15:9, pp. 1277-88.

Jemphrey, A. and Berrington, E. (2000), 'Surviving the Media: Hillsborough, Dunblane, and the Press', Journalism Studies, 1:3, pp. 469-83. 
Joye, S. (2010), 'De Media(de)constructie van Rampen. Onderzoek naar de Selectie en Berichtgeving van Rampen in Vlaamse Nieuwsmedia' [On the Media (De)construction of Disasters], Tijdschrift voor Communicatiewetenschap, 38:2, pp. 139-55.

(2012), Suffering as a Discipline? Scholarly Accounts on the Current and Future State of Research on Media and Suffering, London: Media@LSE Electronic Working Papers Series (23).

(2014), 'Drawing the Thin Line: Reflections on News Media's Use of User-Generated Content in Reporting on a National Disaster', in G. Cooper (Ed.), The Future Of Humanitarian Reporting, London: Centre for Law, Justice and Journalism, City University London.

Kempe, M. (2007), 'Mind the Next Flood! Memories of Natural Disasters in Northern Germany from the Sixteenth Century to the Present', The Medieval History Journal, 10:1/2, pp. $327-54$.

Kitch, C. (2003), 'Mourning in America: Ritual, Redemption and Recovery in News Narrative after September 11', Journalism Studies, 4:2, pp. 213-24.

Kitch, C. and Hume, J. (2007), Journalism in a Culture of Grief, New York, NY: Routledge.

Maercker, A. and Mehr, A. (2006), 'What if Victims Read a Newspaper Report about their Victimization? A Study on the Relationship to PTSD Symptoms in Crime Victims', European Psychologist, 11:2, pp. 137-42. 
Moeller, S. D. (2002), 'A Hierarchy of Innocence. The Media's Use of Children in the Telling of International News', The International Journal of Press/Politics, 7:1, pp. 36-56.

Nguyen, V. T. (2009), 'Remembering War, Dreaming Peace. On Cosmopolitanism, Compassion and Literature', The Japanese Journal of American Studies, 20:1, pp. 149-74.

Pantti, M. (2009), 'Wave of Compassion. Nationalist Sentiments and Cosmopolitan Sensibilities in the Finnish Press Coverage of the Tsunami Disaster', in U. Kivikuru and L. Nord (eds.), After the Tsunami. Crisis Communication in Finland and Sweden, Göteborg: Nordicom, pp. 83-106.

Pantti, M. and Sumiala, J. (2009), 'Till Death do Us Join: Media, Mourning Rituals and the Sacred Centre of the Society', Media, Culture \& Society, 31:1, pp. 119-35.

Pantti, M. and Wahl-Jorgensen, K. (2007), 'On the Political Possibilities of Therapy News. Social Responsibility and the Limits of Objectivity in Disaster Coverage', Studies in Communication Review, 1, pp. 3-25.

Pantti, M., Wahl-Jorgensen, K., and Cottle, S. (2012), Disasters and the Media. New York, NY: Peter Lang.

Perez-Lugo, M. (2004), 'Media Uses in Disaster Situations: A New Focus on the Impact Phase', Sociological Inquiry, 74:2, pp. 210-25. 
Ploughman, P. (1995), 'The American Print News Media 'Construction' of Five Natural Disasters', Disasters, 19:4, pp. 308-26.

(1997), 'Disasters, the Media and Social Structures', Disasters, 21:2, pp.118-37.

Raphael, B. (1986), When Disaster Strikes. How Individuals and Communities Cope with Catastrophe, London: Hutchinson.

Rentschler, C. A. (2010), 'Trauma Training and the Reparative Work of Journalism', Cultural Studies, 24:4, pp. 447-77.

Robinson, S. (2009), “If You Had Been With Us”: Mainstream Press and Citizen Journalists Jockey for Authority over the Collective Memory of Hurricane Katrina', New Media \& Society, 11:5, pp. 795-814.

Shearer, A. (1991), Survivors and the Media. London: Broadcasting Standards Council.

Thumim, N. (2010), 'Self-Representation in Museums: Therapy or Democracy?', Critical Discourse Studies, 7:4, pp. 291-304.

van der Velden, P. G. and van Middendorp, H. (2008), 'Rampen en Calamiteiten', Psychologie \& Gezondheid, 36:3, pp. 101-4.

Vasterman, P. (2008), 'Media en Rampen', Psychologie \& Gezondheid, 36:3, pp. 105-10. 
Walter, T., Littlewood, J., and Pickering, M. (1995), 'Death in the News. The Public Invigilation of Private Emotion', Sociology, 29:4, pp. 579-96.

Wardle, C. (2007), 'Monsters and Angels. Visual Press Coverage of Child Murder in the USA and UK, 1930-2000', Journalism, 8:3, pp. 263-84.

Wayment, H. A. (2004), 'It Could Have Been Me. Vicarious Victims and Disaster-Focused Distress', Personality and Social Psychology Bulletin, 30:4, pp. 515-28.

Wijfjes, H. (2002), 'De Ramp tussen Werkelijkheid en Constructie', Tijdschrift voor Mediageschiedenis, 5:2, pp. 3-10.

Willis, W. J. (2010), The Mind of a Journalist: How Reporters View Themselves, Their World, and Their Craft, London: Sage.

Zelizer, B. (1998), Remembering to Forget: Holocaust Memory Through the Camera's Eye, Chicago: University of Chicago Press.

\section{Contributor details}

Stijn Joye (Ph.D., Ghent University, 2010) is an Assistant Professor at the Department of Communication Sciences (Ghent University, Belgium) where he is a member of the Centre for Cinema and Media Studies (CIMS), the Center for Journalism Studies (CJS) and the Health, Media \& Society $(H M \& S)$ research group. He was also a lecturer at Erasmus University Rotterdam (The Netherlands, 2010-2011) and a Visiting Fellow at London School of Economics and Political Science (United Kingdom, 2012). His areas of research and 
publication include international news, the representation of distant suffering and the concept of artistic imitation in film.

\section{Contact:}

Stijn Joye, Korte Meer 7-11, 9000 Gent, Belgium.

Stijn.Joye@UGent.be

\section{Notes}

${ }^{1}$ All excerpts from the news reports were translated from Dutch by the author. 